\title{
Additive Manufacturing as a strategic tool for industrial competition
}

\author{
Francesco G. Sisca, Cecilia M. Angioletti, Marco Taisch, and James A. Colwill
}

\begin{abstract}
Additive Manufacturing (AM), often misleadingly referred to as 3D Printing (3DP), comprises of a group of technologies whose initial inception occurred over thirty years ago within the product design and development applications for the rapid prototyping of concepts, primarily using polymeric materials. Over the past few years AM development has increased exponentially and 3D Printing has expanded to include new areas of research such as 4D Printing, Nano AM, Contour Crafting and so on. However, a proper understanding of the technology's actual and potential benefits to industrial manufacturing has not been approached by practitioners and researchers in detail and industrial end-users risk missing the opportunity to make competitive choices due to the lack of an impartial and realistic overview. Real and tangible industrial benefits are often misunderstood due to the dissemination of information delivered with a mindset grown on a maker-side market, which misses to scope for AM in industrial applications. The aim of the paper is presenting a detailed overview of AM applications in the industrial world, focusing on the likely impacts on organizations and, moreover, to highlight and discuss the potential employments of the technology within the industrial value chain.
\end{abstract}

Keywords - Industrial Additive Manufacturing, Additive Layer Manufacturing, Applications, State of the art

\section{INTRODUCTION}

$\mathrm{T}$

ODAY's global markets are increasingly being driven by demand for product customization whilst products life cycles are shrinking and customers awareness is increasing resulting in a greater uncertainty in market demand [1]. Moreover, in last three decades mass production has moved from old industrial countries to developing ones [2] and western manufacturing enterprises are undergoing a transformation from a pure product based value creation approach towards a more service oriented marketing model [3][4]. Thus, industries are asked to deliver low volume production of more innovative custom-made and sustainable products with high added value [2][5]. Satisfaction of the customer doesn't lead anymore to the only fulfillment of primary needs, but to providing secondary services around the goods themselves, which is not achievable within the old business models[6][7].

Among all the key enabling technologies (KET) [8][9] that push industries towards these transformations, AM has the potential for a paradigm change moving manufacturing away from mass production in large factories with dedicated expensive tooling to world of mass customization and

Submitted on the 30 ${ }^{\text {th }}$ of April 2016.

F.G. Sisca, C.M. Angioletti, M. Taisch are with Politecnico di Milano, Department of Management, Economics and Industrial Engineering, Milano, Italy (e-mail: francescogiovanni.sisca@polimi.it, ceciliamaria.angioletti@polimi.it, marco.taisch@polimi.it). distributed manufacturing [10].

AM, often misleadingly referred to as 3D Printing, comprises of a group of technologies whose initial inception has occurred at least thirty years ago within the design and development applications for the rapid prototyping of design concepts, primarily using polymeric materials [11] as support to the design process. From its very beginning, AM has been used with the aim of accelerating the product innovation cycle [12], but over the years the developments in processes, materials, and technologies have led to several incremental successful applications on end-use products manufacturing (e.g. CFM fuel nozzle for LEAP engine by GE [13]). The acceleration of developments in AM have increased exponentially and initial terminologies such as 3D Printing have expanded rapidly to include 4D Printing, Nano AM, Contour Crafting and so on [13]. However, a proper understanding of the scope of Additive Manufacturing Technologies (AMTs) industrial applications including the understanding of its potential benefits to industrial manufacturers has not been fully highlighted yet and industrial end-users risk missing opportunities due to a lack of awareness and proper understanding. This paper presents the major peculiarities of AM applications in industrial sectors, focusing on the impacts on organizations and assesses the potential applications in several stages of the industrial value chain. The work is structured as follows: In section 2 industrial AM peculiarities are presented while, in section 3 a comprehensive discussion over main industrial applications is given. In section 4 real impacts and advantages on manufacture are examined while in section 5 trends and challenges are faced with. Finally, in section 6 conclusions are inferred and the important topics for the future research discussed.

\section{INDUSTRIAL AM PECULIARITIES}

The F42 Committee on Additive Technologies of the American Society for Testing and Materials (ASTM) together with the International Organization for Standardization (ISO) issued the standard ISO/ASTM52921-1 according to which AM is defined as the "process of joining materials layer upon layer in order to make physical objects directly from 3D model data" [14]. The term has been given as indicating the opposed concept respect to traditional manufacturing methodologies, which consist in removing material from a bulk (i.e. subtractive manufacturing).

J. A. Colwill is with the Loughborough University, School of Mechanical and Manufacturing Engineering, Loughborough, United Kingdom (e-mail: j.a.colwill@lboro.ac.uk). 
According with W. Frazier [15], AM is "an innovative technology in the manufacture and repair of parts, which represents a revolutionary advance in the way we design, manufacture and maintain many products". The term Additive Manufacturing refers to processes which, compared to the traditional technologies (i.e. subtractive and formative [2]), produce layer by layer physical objects directly from Computer-Aided Design (CAD) data. AM process starts from the design in the form of a computerized 3D model, which can be directly transformed into a finished product through several phases, without the use of molds, additional fixtures and cutting tools [16]. AM comprehends a varied group of technologies, included 3D Printing (3DP), which is, along with all the others, one of the technologies, whose basic characteristic is creating net shapes by adding material layer-by-layer. The manufacturing accuracy, the available choice of materials, the build rates, the mechanical properties and the finish quality of the additively manufactured parts can largely vary and imply different corresponding application fields [17]. In fact, behind the well-known denomination of AM, there is such a variety of different manufacturing processes that researchers cannot refer to as a whole [17]. As a matter of facts certain technologies and applications concern business to consumer (B2C) logics while other ones industrial markets. The investigation perspective moreover may be carried on through consumer market standpoint or through industrial focus, whether metal based or polymer based [13]. Industrial AM deals with the manufacturing companies that have adopted such technologies to provide a more valuable services and products to their clients in a business to business (B2B) perspective.

Categorizing current industrial additive manufacturing processes may be done considering materials, applications and the commercial technologies offered.by Original Equipment Manufacturers (OEM). In order to enable researchers and practitioners to discuss a category of manufacturing applications and embedded technologies rather than commercial solutions, ASTM have provided a structure "for grouping current and future AM machine technologies" [18] in seven different industrial AM technologies. Each of those responds to a specific AM application within the industrial sectors, that have been developed over time, starting from the manufacture of prototypes (Rapid Prototyping - RP), to the production of tools (Rapid Tooling - RT) and real manufacture of finished products (Rapid Manufacture - RM), till coming to address the end of life phase of manufactured assets (in this work referred to as Maintenance \& Repair - M\&R) . For each industrial technology may exist several commercial solutions, whose ownership strictly belongs to the OEM that have developed and made the AM system available on the market. The ratio between AM industrial technologies and technological commercial solutions is "1:few", while the ratio between technological commercial solutions and OEM is " $1: 1$ " as long as patents will be strictly copyrighted (e.g. FDM patent expired in 2006-2007 time frame). It is clear that the industrial market of OEMs is a very narrow one and it is still a bridle to the technology spread.
TABLE 1 summarizes the ISO/ASTM standard AMTs categories in correspondences with commercial technological solutions.

TABLE 1

AMTS CATEGORIES - COMMERCIAL TERMS CORRESPONDENCES [10]

\begin{tabular}{|c|c|c|c|}
\hline $\begin{array}{l}\text { Industrial } \\
\text { application }\end{array}$ & $\begin{array}{l}\text { ASTM Classification } \\
\text { (AM industrial process) }\end{array}$ & \begin{tabular}{|c|} 
Commercial \\
Technological \\
Solution \\
\end{tabular} & Material \\
\hline \multirow{4}{*}{$\mathrm{RM} / \mathrm{RT}$} & \multirow{4}{*}{ Powder Bed Fusion } & DMLS & M \\
\hline & & SLM & M \\
\hline & & EBM & M \\
\hline & & SLS & $\mathrm{P}$ \\
\hline \multirow{2}{*}{$\begin{array}{l}\text { Maintenance \& } \\
\text { Repair }\end{array}$} & \multirow{2}{*}{ Directed Energy Deposition } & DMD & M \\
\hline & & LENS & M \\
\hline $\mathrm{RP}$ & Material Jetting & Polyjet & PP \\
\hline $\mathrm{RP}$ & Binder Jetting & 3DP & $\mathrm{P} / \mathrm{M}$ \\
\hline $\mathrm{RP}$ & Material Extrusion & FDM & $\mathrm{P}$ \\
\hline \multirow{2}{*}{$\mathrm{RP}$} & \multirow{2}{*}{ VAT Photopolymerisation } & SL & PP \\
\hline & & DLP & PP \\
\hline $\mathrm{RP}$ & Sheet Lamination & LOM & M \\
\hline
\end{tabular}

M: Metal, P: Polymer, PP: Photopolymer

In industrial AM applications, post processing activities are particular activities carried on in order to confer the produced part with functionalities and requirements needed. Common post processing activities are often done in order to enhance the surface, strength properties of the part (e.g. thermal processes, isostatic compression, etc.), or remove any support material (needed to create accessories structures stabilizing the part during the process and realized during the process itself). In this regard economic analysis might show limitations in specific AMTs uses due to the reduction of the technology benefits by the post processing activities costs [19].

\section{INDUSTRIAL AM APPLICATIONS}

$\mathrm{AM}$ in terms of intended use, might be identified into four broad categories: Prototyping, Tooling, Production of near-net shape products, Maintenance and Repair, listed in chronological respect of their appearance in the AM technologies development (Figure 1)

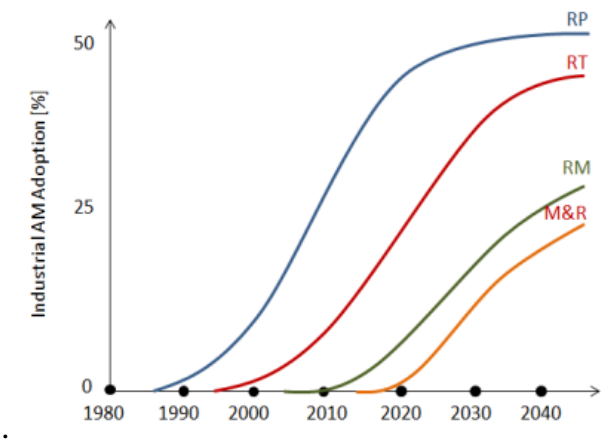

Figure 1 - Chronological adoption of industrial AM 
Historically, AM appears in the industrial sectors with the aim of creating visual models within the design process of a new product and for the production of representative or functional (fit \& assemblies) models. This application is addressed as Rapid Prototyping (RP) and its output is "meant only to accelerate the development phase (time-to-market) of a product and under no circumstance is comparable to the end product regarding quality, material and durability” [2][20]. RP output includes communication models, visual aids, sales models, preproduction parts, etc.

AM is employed in industrial sectors also to produce additively manufactured net-shapes used as sacrificial for the production of molds and tools or as tools and molds themselves [4]. This application refers to Rapid Tooling (RT) and can be considered one of the main industrial applications of AM technologies. RT may consist in directly producing tools such as jigs, fixtures, templates, gauges and drill guides which are subjected to sporadic and low quantities demand. The aim in this case is to avoid overly expensive and time-consuming production through traditional manufacturing processes.

RT can also aim to quickly realize molds or master patterns instrumental to manufacture molds. The former approach is called direct $R T$, the latter indirect $R T$ [11][12][13]. One of the advantages of the use of those technologies in RT is the possibility to create inner conformal cooling channels within the mold, and virtually free formed according to thermodynamic needs, that allow to remove the heat faster and more efficiently then straight-line channels such as those available with traditional manufactured molds. Moreover, this cooling optimization results not only in the reduction of injection operations' cycle times and the increasing of life cycle, but also in the improved quality of the final parts [10].

With the enrichment of materials availability and the development of AM processes and machines, sectors as aerospace and automotive have been hosted several cases of final components manufacturing. This application is known as Rapid Manufacturing (RM) or Direct Digital Manufacturing (DDM) [14] and concerns the manufacture of functional products and components. The core activities enabling RM are Design for Additive Manufacturing (DFAM) and postprocessing activities [13][16][20]. As a matter of facts, in order to produce through industrial AMTs, the design of the final objects should be thought for RM, going through concepts of part consolidation, topology optimization, trabecular, biomimic and honeycomb structures [13][16][20].

Other AM applications, increasingly profitable for companies, deal with repair and maintenance activities (M\&R) of existing industrial products (e.g. repair and retrofitting worn parts of aircrafts in environmental contexts difficult to be accessed). This activity is very convenient in those cases where huge products have to be repaired or fitted, and for which it is difficult to apply a spare parts logic. In these cases, the damaged part is localized and turns out to be more convenient to intervene with an additive manufacturing technique so that, in the case of metal parts, it is possible to apply a metallurgical bonding rather than a mechanical bonding (i.e. welding operation) by adding layers of the same material of the worn parts. [14][15].

Moreover, some examples of integration between conventional machining processes (such as milling, turning, etc.) and additive technologies (i.e. Directed Energy Deposition) to realize hybrid machines have been presented on the market in the recent past, but their effectiveness (both technological and economical) has still to be proved.

\section{IMPACTS AND ADVANTAGES ON MANUFACTURE}

In AM impacts on industrial fields are theoretically powerful and varied and one might group them into two categories: technological and economic impacts. The former concern product and processes while the latter deals with organizational structures and business models. Economic consequences derive from technological aspects and hereinafter are presented and discussed in detail. Other general impacts of AMTs concerning environment and societies are not detailed in this work.

First of all, un-rivalled geometric freedom of design is a typical technological advantage on the product side and is triggered by the absence of need for tooling and molds. Moreover, whatever the complexity of the product, AM systems allow to directly manufacture the physical object part consolidating which means realizing a component just in one manufacturing phase, unlike traditional technologies that require several manufacturing stages to come to the final shape. The lack of tools needed, implies the possibility to follow geometries and specific features that can better satisfy the level of details required by customers. Thus, complexity for free is the possibility to obtain complex geometries disconnected by operational costs and it's typical advantage in AMTs based design and production. Between RP and indirect RT applications, it is worthy of mention master patterns production for secondary tooling processes (i.e. soft RTV tooling and urethane castings).

Specific design logics thought for AM (i.e. DFAM) allow internal features, blind holes, and overhangs together with honeycomb and trabecular structures, which aims at optimizing geometries. Furthermore, all the aforementioned technology features allow managing parts design to come to the final manufacture of a lighter-weight component if compared to traditional manufacturing.

In RM the core concept is that production is driven only by functional requirements of the final product/component rather than by manufacturing constraints.

AM technological unique characteristics lead the technology users to follow strategic benefits when facing with the market [21][5]. In fact, technological aspects and benefits can lead to economic advantages, linked both directly on manufacturing processes management and through organizational structures.

Regarding the manufacturing process technology peculiarity of obtaining net shapes without the mean of molds and tools, among all, means "freeing up working capital within supply chain and reducing business risk in new product innovation"[10]. High investment costs can be thus avoided and more flexible responsiveness to the market demand provided as well. Moreover, designers have the ability to quickly turn 
concepts into 3D models or 3D prototypes, opening up shapes and chasing niche markets that were impossible to go into before [9].

Still on the subject of technological properties, AM production comes to a near $100 \%$ material utilization that accomplish a decrease of material waste in the manufacturing process, as almost the whole amount of material involved contribute to manufacture the final component.

The speed in modifying existing design and the opportunity to quickly come to a first prototype to the final customer through RP makes industrial enterprises able to reduce the time between market request and the part/product delivery, which means reduction of lead time and time to market [9]. In fact, the whole new product development process, compared to traditional manufactured based one, is accelerated along with reaching a high customization due to the AMTs advantage of guaranteeing design flexibility [5].

In a traditional new product development process the prototype is available for consultation with the final customer just after the preparation of molds and tools, which often means weeks or months (Figure 2).

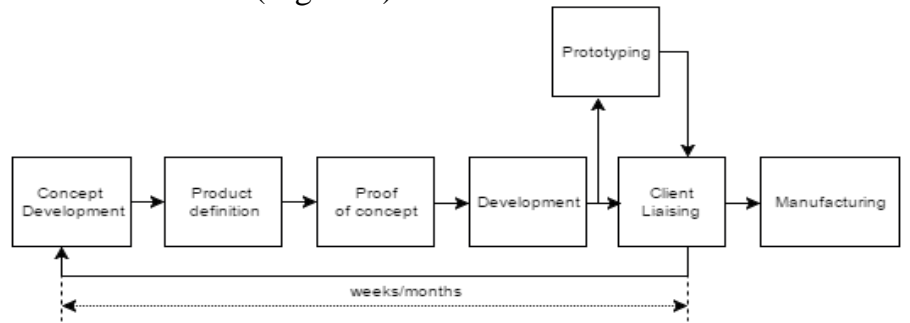

Figure 2 - New Product Development with traditional manufacturing

With AM, whether employed as RT or RP, the process is shortened till obtaining an overall duration of days (Figure 3). Moreover, prototypes can be quickly available to final customer and with " $n$ " iterations the optimum solution can be reached in shorter time and with a higher customer satisfaction (Figure 3).

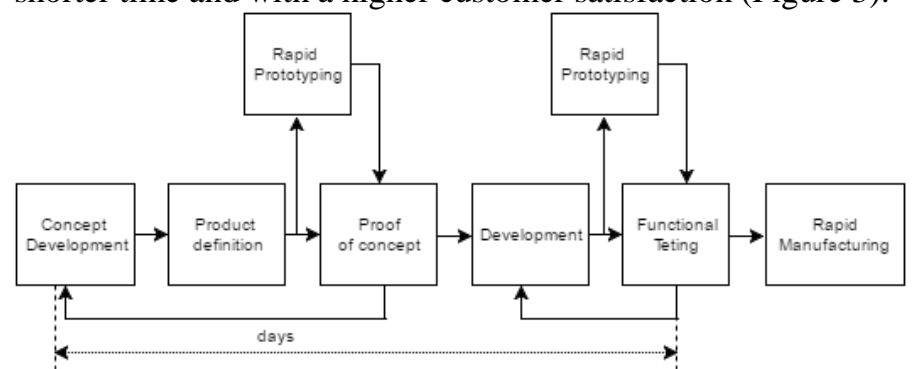

Figure 3 - New Product Development with RP and RM

As AM bases on digitalized information and data, instant and economical customization [5] can be run to better exploit the possibility to fully satisfy the needs disclosed in the mean of realizing low demand quantities of a big variety range of products. Strategic advantages come out together with internal changes on organizations structures and business models.

Technical changes on products and processes impact organizational level in the respect that they induce industries to set business models based on real flexible manufacturing strategies. These strategies are basically on demand manufacturing (ODM) and distributed manufacturing [5][22].

On demand manufacturing permits to make customized products at the desired time and quantity, minimizing warehousing efforts for components and finished products [22]. Trough ODM, industries may simplify the supply chain, reacting more quickly to market changes and modifying production rates to match the actual demand. Beside on demand manufacturing, additive technologies may implies huge changes on supply chain in the respect of their logistics sets as well. More decentralized supply chains can be implemented, thus fostering the creation of distributed manufacturing models, which allows the realization of the finished product near to the point of sale or use [5][22]. Distributed manufacturing strategies even make easier to the manufacturer to understand the customer needs for specific customization.

In fact, these organizational strategies are allowed by a change in industrial supply chains as well.

Traditional supply chains are characterized by centralized flows of goods, which starting from the producer, pass through distribution and retail till arriving to the final client. On the other hand, the industrial customer starts the virtual flow, which is reverse (Figure 4). In AM based supply chain instead both physical and information fluxes are closer to the customer and do not rely just on the producer. In fact, the final customer triggers information flows, which can imply physical production time to time, upon retail or distribution, while all the information of the design come directly from the producer (Figure 4) In Figure 4 solid line represents physical flow while dashed lines information flux.

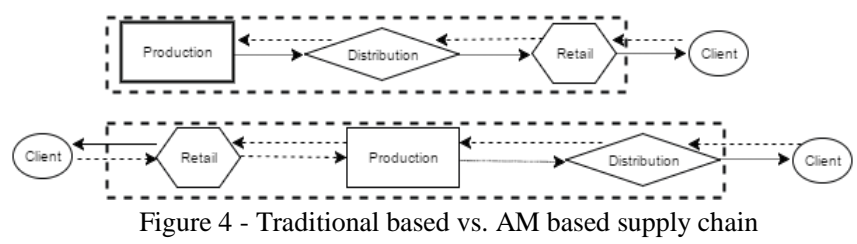

The aforementioned manufacturing strategies amplify the development of AMTs as enabler for products end of life stretch through enhancing spare parts intervention and maintenance activities [13][15]. In this sense, the proximity to plants and shop floors facilitate the $M \& R$ interventions in terms of effectiveness, speed and customization of the intervention itself.

All of these potential benefits on organizational structures, industrial business models and supply chains suggest that disruptive changes can occur on economies and societies. However proper analysis can bring to the state of the art clearer overview.

\section{TRENDS AND CHALLENGES}

Additive Manufacturing (AM) is seen by many as one of the potential game changers of the future industrial markets and for some applications has already reached a certain level of maturity [9]. A growing enthusiasm and an increased adoption of these technologies is occurring all over the world and 
national and international policies are going after the need to boost its development. Up today, among all the most relevant industrial AM projects worth to cite are:

- REPAIR (investigating M\&R application in the aerospace industry),

- SASAM (Support Action for Standardization in AM),

- MANSYS (aims to develop a supply chain managementsystem to boost mass adoption of AM),

- AMAZE (Additive Manufacturing towards Zero waste), and

- BOREALIS (aiming in delivering novel machine with improved throughput, closed loop control producing true net shape products).

AM has the potential to offer significant benefits in a number of industrial sectors including the environmental perspective where future manufacturing will be increasingly measured on its environmental footprint [5]. AM is likely to impacts on organizations in the sense that it would dramatically change their business models, shift their production locations, and shrink their supply chains [23]. The pace of development and implementation (of AM) is likely to widely vary considering different sectors and manufactured products. However in order to benefit more from the opportunities that AMTs offer, new organizational structures and Business Models have to be investigated, discussed and developed.

Such Business Models are oriented on service design, value co-creation, strong networks, and on economy of scope rather than on the traditional concepts of centralization and economy of scale [24].

The combination of RP, RT and RM seems will drive to restructure modern supply chains "regarding lead time, operations, logistics, capital investment and location of production facilities” [12].

The future developments of additive technologies for manufacturing should be targeted toward technological aspects as well [25]. There are some significant limitations to be eliminated in order to have wider and more effective application of Additive manufacturing in industry. First of all machine issues such as size, process control, integration with other manufacturing processes and deposition ratio should be tackled. Nowadays, the part size rarely reach 1 meter, (averaging on 200-350 mm), depending on machine type and process thus bigsized parts which are needed in certain sectors are difficult to be produced. Proper process control moreover is another issue as, especially for not-prototype parts to be used in high performance/critical applications (e.g. aerospace, racing, biomedical), quality and repeatability of the operations are crucial aspects. Integration of additive technologies with other manufacturing processes can be achieved bot at machine level (i.e. hybrid manufacturing) and at system level (i.e. production chains integrating additive machines as mass-customization enablers) while deposition ratio today is very low as usually is less than $50 \mathrm{~cm} 3 /$ hour for operation on metals, and thus should be significantly increased to reach an extensive application in sectors closer to mass production.

Also under respect of materials there are certain drawbacks to be overcome. First of all an increase of the range availability is necessary in order to decrease the costs and boost the competitiveness of new manufacturing solutions based on additive technologies. Secondly production methodologies, especially for metal powders, have to be enhanced toward more efficient systems (under quantity, energy efficiency and quality aspects). The range of processed materials have to be extended as well, both for the well consolidated ones (i.e. metals, polymers, composites, ceramics) and for the future ones (e.g. food, bio-structures).

In terms of products AM push toward the need of rethinking products already existing on the market under an "additive perspective", which may allow to reach weight reduction, increase of performances, sustainability, optimization of geometry and material utilization Designers and engineers are asked to create new generations of product through the principles of "free forming" and "net-shape" and using AMTs capability to work with "difficult-to process" and unusual materials. Thus, hybrid products integrating "additively made” parts with others characterized by different manufacturing process or material can be designed, as well as integrate new functions such as sensors and ICT-based features, within the product.

\section{CONCLUSIONS AND CONSIDERATIONS}

In certain applications AM has changed the new product development and manufacturing stages. Several benefits have been achieved by the use of AMT within the shop floors of several industries. Whether the aim is to speed up the lead time to market or to face with complexity, the AM systems directly produce the net-shape in a single process unlike the traditional production technologies. Traditional stages such as foundry and assembly activities might be no longer required in the comingfuture industrial supply chains. While making highly customized products, in the exact quantity at the desired time, in the location close to the customer might yet be possible whenever certain technological drawbacks would be overcame.

However, the full potential of the technology can be transformed in actual economic benefits to industries only if also employers, designers, and managers would reach the proper forma mentis and would be provided with the proper tols and methodologies.

Grounded on this belief this informative article aimed to provide the AM state of the art with a clear and holistic understanding about the benefits, characteristics and applications of industrial Additive Manufacturing. The core concepts belonging to this field of research have been consolidated and explained in a brief and synthetic format.

Future efforts of the whole AM-based researchers and information providers ecosystem should aim not only at overcoming current technological limits but also at supporting the management level of industrial organizations to deal with the integration of AMTs in their manufacturing strategies. Therefore, the impacts of AMTs on products, production systems, organizations, economies and environment have to be considered and customized methodologies specifically thought for AM delivered to the state of the art. Moreover different business models both currently available to new incomers and in a "to be" perspective should be investigated. Upcoming 
papers of the authors will be first of all dealing with expanding and detailing each of all aspects presented in this work, secondly concerning the implementation of a Cartesian space for the positioning of players in AM industrial supply chain and the identification of the main industrial archetypes. The Life Cycle Assessment (LCA) traditional methodology will be also investigated, so that the specific requirements for Additively Manufactured products will be presented and discussed.

\section{NOMENCLATURE}

$\begin{array}{ll}\text { AM: } & \text { Additive Manufacturing } \\ \text { AMT: } & \text { Additive Manufacturing Technology } \\ \text { ALM: } & \text { Additive Layered Manufacturing } \\ \text { CNC: } & \text { Computer Numerical Control } \\ \text { RT: } & \text { Rapid Tooling } \\ \text { RP: } & \text { Rapid Prototyping } \\ \text { RM: } & \text { Rapid Manufacturing } \\ \text { M\&R: } & \text { Maintenance and Repair } \\ \text { RTV: } & \text { Room Temperature Vulcanization } \\ \text { DMLS: } & \text { Direct Metal Laser Sintering } \\ \text { SL: } & \text { Stereolitography } \\ \text { FDM: } & \text { Fused Deposition Modeling } \\ \text { LOM: } & \text { Laminated Object Manufacturing } \\ \text { EBM: } & \text { Electron Beam Melting } \\ \text { 3DP: } & \text { Three Dimensional Printing } \\ \text { SLM: } & \text { Selective Laser Melting } \\ \text { CAD: } & \text { Computer Aided Design } \\ \text { ASTM: } & \text { American Society for Testing and Materials } \\ \text { DMD: } & \text { Direct Metal Deposition } \\ \text { LENS: } & \text { Laser Engineering Net Shaping } \\ \text { DLP: } & \text { Digital Light Processing } \\ \text { OEM: } & \text { Original Equipment Manufacturer } \\ \text { ODM: } & \text { On Demand Manufacturing } \\ & \end{array}$

\section{ACKNOWLEDGMENTS}

The authors want to gratefully acknowledge and thank for their availability and contribution the Italian Association of Additive Manufacturing Technologies, AITA-Associazione Italiana Tecnologie Additive, and particularly Dr. Enrico Annacondia, and the Wohlers Associates, Inc., particularly Mr. Tim Caffrey.

\section{REFERENCES}

[1] F. G. Sisca, M. Fiasché and M. Taisch, "A Novel Hybrid Modelling for Aggregate Production Planning in a Reconfigurable Assembly Unit for Optoelectronics”, ICONIP 2015, Part II, LNCS 9490, pp.571-582, 2015.

[2] M. Thymianidis, C. Achillas, D. Tzetis and E. Iakovu, "Modern Additive Manufacturing Technologies: An Up-to-Date Synthesis and Impact on Supply Chain Design”, 2nd Olympus Int. Conf. on Supply Chains, Katerini, Greece, October 5-6, 2013.

[3] S. Vandermerwe and J. Randa, "Servitization of business: Adding value by adding services”, European Management Journal, vol. 6, no. 4, pp. 314-324, Apr. 1988.

[4] S.L. Vargo and R. F. Lusch, "Evolving to a new dominant logic for marketing”, Journal of Marketing, vol. 68, no.1, pp. 1-17, Jan. 2004.

[5] S. Mellor, L. Hao and D. Zhang, "Additive Manufacturing: A framework for implementation”, Int. J. Production Economics, vol. 149, pp. 194-201, Mar. 2014.

[6] J. Manyika, J. Sinclair, R. Dobbss, G. Strube, L. Rassey, J. Mischke, J. Remes, C. Roxburgh, K. George, D. O’Halloran and S. Ramaswamy. (2012, Nov.). Manufacturing the future: The next era of global growth and innovation. McKinsey Global Institute. Washington DC, USA. [Online]. $\quad$ Available: http://www.nist.gov/mep/data/upload/Manufacturing-the-Future.pdf

[7] M. Garetti and M. Taisch, "Sustainable manufacturing: trends and research challenges”, Production Planning \& Control, vol. 23, no. 2-3, pp. 83-104, Mar. 2012.

[8] European Commission. Key Enebling Technologies. [Online]. Available: http://ec.europa.eu/growth/industry/key-enablingtechnologies/index_en.htm , retrieved on Apr. 2016.

[9] European Commission. (2014, Jun). Additive Manufacturing in FP7 and Horizon 2020, Report from the EC Workshop on Additive Manufacturing held on 18 June 2014. [Online]. Available: http://www.rmplatform.com/linkdoc/EC\%20AM\%20Workshop\%20Report\%202014.p df

[10] R. Quarshie, S. Machachlan, P. Reeves, D. Whittaker and R. Blake. (2012, Sept.). Shaping Our National Competency in Additive Manufacturing. The Additive Manufacturing Special Interest Group for the Technology Strategy Board. UK. [Online]. Avaialable: https://interact.innovateuk.org/documents/1524978/1866952/Shaping\%2 0our\%20national\%20competency\%20in\%20additive\%20manufacturing

[11] A.R. Mashhadi, S. Behdad and B. Esmaeilian, "Impact of Additive Manufacturing adoption on future supply chains", Proceedings of the ASME 2015 International Manufacturing Science and Engineering Conference Charlotte, North Carolina, USA, Jun. 8-12, 2015.

[12] Ch. Achillas, D. Aidonis, E. Iakovou, M. Thymianidis and D. Tzetzis, “A methodological framework for the inclusion of modern additive manufacturing into the production portfolio of a focused factory", Journal of Manufacturing Systems, vol. 37, pp. 328-339, Oct. 2015.

[13] T. Caffrey and T. Wohlers. Wohlers Report 2015: Additive Manufacturing and 3D Printing, State of the Industry. Ft. Collins, CO: Wohlers Associates. May 2015.

[14] W. Frazier, "Metal Additve Manufacturing: A Review”, JMEPEG, vol. 23, no.6, pp. 1917-1928, Jun. 2014.

[15] W. Frazier, "Direct Digital Manufacturing of metallic components: Vision and Roadmap”, Solide Freeform Faprication Proceedings, pp. 717732, International Solid Freeform Fabrication Symposium, Austin, 2010

[16] I. Gibson, D.W. Rosen and B. Stucker, "Additive Manufacturing Technologies: Rapid Prototyping to Rapid Manufacturing”, 2nd Edition, Springer, 2009

[17] F. Piller, C. Weller and R. Kleer, "Opportunities and Challenges from the Perspective of Economics and Management”, Chapter 4, Advances in Production Technology, pp. 39-48, 2015

[18] ASTM, F2792-12a. Standard Terminology for Additive Manufacturing Technologies. [Online]. Available: http://www.astm.org/FULL_TEXT/F2792/HTML/F2792.htm\#s00200, retrieved on April 2016

[19] A. Srinath and S. Dubey, Effective and Efficient Additive Manufacturing Ecosystems, 2014

[20] F. Feenstra, B. Holmer, H. Pohl, G. Tromans, N. Moos and B. Mieritz, "RP, RT, RM trends and developments/research survey", Technical Report, RAPTIA project, 2002

[21] J. Holmstrom, J. Partanen, J. tuomi and M. Walter, "Rapid Manufacturing in the spare parts supply chain: alternative approaches to capacity deployment”, Journal of Manufacturing Technology Management, vol. 7, no. 3-4, pp. 169-175, 2010

[22] J.Scott, N. Gupta, C. Weber, S. Newsome, T. Wohlers and T. Caffrey, "Additive Manufacturing: Status and Opportunities, Science and Technology Policy Institute”, Washington, DC, pp. 1-29, 2012

[23] T. Ratinho, R. Harms and S. Walsh, "Structuring the Technology Entrepreneurship publication landscape: Making sense out of chaos. Technological forecasting and social change", vol. 100, pp. 168 175, 2015

[24] J. Fenn and M. Raskino. Mastering the Hype Cycle: How to Choose the Right Innovation at the Right Time. Gartner, Harvard Business Press, 2008

[25] Airi, Le innovazioni del prossimo futuro. Tecnologie proprietarie per l'industria. vol. 2012, pp 747-753, IX Ed. 2016 